Research Article

\title{
Damage Assessment of an RC Pier under Noncontact Blast Loading Based on $P$-I Curves
}

\author{
Lu Liu $(\mathbb{D}$, Zhouhong Zong $(\mathbb{D}$, Biao Tang, and Minghong Li \\ School of Civil Engineering, Southeast University, Nanjing 211189, China \\ Correspondence should be addressed to Zhouhong Zong; zongzh@seu.edu.cn \\ Received 8 February 2018; Revised 5 June 2018; Accepted 5 July 2018; Published 16 August 2018 \\ Academic Editor: Nuno M. Maia \\ Copyright $\odot 2018 \mathrm{Lu}$ Liu et al. This is an open access article distributed under the Creative Commons Attribution License, which \\ permits unrestricted use, distribution, and reproduction in any medium, provided the original work is properly cited.
}

\begin{abstract}
Since the 9.11 attacks in New York, terrorist attacks, military strikes, and accidental explosions have caused serious damage to various infrastructures around the world. Accidental traffic explosions in bridge engineering have occurred frequently due to the increasing firework truck on the bridge and heavy fuel oil ships under the bridge. Besides, intentional car bomb explosions in terrorist attacks and military assaults are significant threats to the bridge structure. Bridge pier is a particularly important component of the overall bridge structure due to its vertical support capacity. Therefore, the damage of reinforced concrete (RC) piers under blast loading should be studied. In this paper, the pier is simplified as a single degree of freedom (SDOF) system based on energy equality, and the blast loading distribution on the surface of the pier is simplified as a uniform distribution. Then, the $P-I$ curves of an RC pier are obtained based on the SDOF system and a uniform distribution blast loading to quickly evaluate the damage extent of an RC pier so that the $P-I$ curves and fitting formulas for different damage extents can be used for practical engineering. After a numerical simulation verification, the $P$-I curves and fitting formulas based on the simplified method can supply a rapid and effective method for engineers to assess the postexplosive damage of an RC pier.
\end{abstract}

\section{Introduction}

Since the 9.11 attacks in New York, terrorist attacks, military strikes, and accidental explosions have caused serious damage to various infrastructures around the world [1]. In recent years, accidental traffic explosions in bridge engineering have occurred frequently due to the increasing firework truck on bridges and heavy fuel oil ships under the bridge. Besides, intentional car bomb explosions in terrorist attacks and military assaults are significant threats to the bridge structure $[2,3]$. Bridge pier is a particularly important component for the overall bridge structure due to its vertical support capacity; therefore, it is more vulnerable to be damaged under blast loading.

There are some achievements on dynamic response, failure modes, and protective measures for structures under blast loading at home and abroad; however, there are lack of valid and fast postexplosive evaluation methods for structural damage. Therefore, it is unpredictable to assess the damage extent of the engineering structure for engineers in a simplest way. Pressure-impulse $(P-I)$ curve has been put forward in the second world war [4] and became a current accepted method for structural postexplosive damage assessment [5], which represents an identical structural damage extent under blast loading. $P$ - I curve is a changeless curve for each structure, so the structural postexplosive damage extent can be confirmed quickly after getting the $P-I$ curve.

$P-I$ curve can be obtained primarily by test, numerical simulation, and theoretical analysis. Test method can reliably get the $P$ - $I$ curve for a specific structure by a large number of blasting experiments, in which overpressure and impulse on the structural surface at different damage extents are obtained. However, it is an economically and logistically poor choice and is hard to apply to actual engineering. Due to the large cost, few researchers use this method to get the P-I curve. Wesevich and Oswald [6] conducted a blasting experiment on a concrete block wall by a shock wave tube, in which there were 236 overpressure and impulse data points of the walls so that the P-I curve of the concrete block wall 
could be determined. However, there are differences between an actual explosive wave and the simulated shock wave generated by the shock wave tube.

Numerical simulation can also be used to get the structural P-I curve; however, it requires a complete understanding of the structure in order to determine numerical parameters accurately. In addition, a large amount of calculation work and better computing equipment are also important conditions to gain an exact $P-I$ curve. Krauthammer et al. [7] have determined the $P-I$ curves of an RC beam, a slab, columns, and other structures by simulation. Dragos et al. [8] have evaluated the damage extent of an ultrahigh-performance concrete (UHPC) slab under blast loading and determined the $P-I$ curves in different parameters. Mutalib and Hao [9] have evaluated the damage extent of a fiber-reinforced concrete column under blast loading and determined the $P-I$ curves by LS-DYNA according to the residual bearing capacity of columns. Column dimensions, material strength, fiber thickness, and other parameters were taken into consideration. Shim et al. [10] have assessed the blast-resistance performance of a multilayer foamed aluminum slab considering a material dynamic increase factor (DIF) at a high strain rate and obtained the $P-I$ curve of the aluminum slab by finite element software. Domestically, Shi et al. [11] have studied RC columns under blast loading and determined the $P$ - $I$ curves from residual bearing capacity by ANSYS/LS-DYNA. There is no doubt that simulation is a quite accurate and low cost method to get the $P$-I curve under the condition of exact model parameters; however, it is hard to guarantee that the simulated structure and real structure are identical. Moreover, it is also a much more time-consuming method to evaluate structural postexplosive damage for engineers.

Additionally, theoretical analytical can rapidly evaluate the structural damage extent, simplifying the structural force system. Firstly, the structural dynamic response is the most important for damage assessment, which can be got by a simplified force system. Equivalent single degree of freedom (SDOF) system has become the most extensive analytical method due to its ability to determine quickly the structural $P$ - $I$ curves. Li and Meng [12] have determined the structural $P$ - $I$ curves by dimensional analysis and the SDOF system. Fallah and Louca [13] have conducted research on $P-I$ curves based on elastic plastic hardening and the softening equivalent SDOF model, which can be divided into six phases, such as the elastic phase, elastic-plastic hardening phase, elastic-plastic softening phase, rigid plastic hardening phase, and rigid plastic softening phase. Ma et al. [14] have conducted an assessment on a consolidated beam at both ends based on the equivalent SDOF system considering flexural failure and shear failure. Colombo and Martinelli [15] have determined the $P-I$ curves of RC plates and fiber RC circular plates based on the SDOF system with various diameters. Dragos and $\mathrm{Wu}$ [16] performed normalized processing on the structural $P-I$ curves by the SDOF system so that the $P-I$ curve could be applied to any impact loading. Wang et al. [17] used the SDOF system to study the $P-I$ curves of RC slabs and beams with flexure failure and shear failure and analyze the relationship between different physical parameters and the $P-I$ curve. This method originates from a basic mechanical model and simplifies the complex structural system; therefore, it can be used to calculate complex explosive systems rapidly and effectively due to its simple application.

Currently, the P-I curve is believed to be an effective method to determine the damage assessment under blast loading in the engineering field. However, there are advantages and disadvantages in the above three methods to determine the $P-I$ curve. Although the test method is quite accurate, it is also expensive. Furthermore, the simulation method is the most economical but is the most timeconsuming [18, 19]. Last, the theoretical analytical method is the simplest and fastest method for engineers and became the most versatile method in the engineering field due to ignoring the flexural shear failure $[20,21]$. Therefore, the equivalent SDOF method is used to calculate the structural dynamic response and determine the $P$ - $I$ curve of a bridge pier in this paper so that the damage extent can be quickly evaluated. Also, the numerical model is built to validate the SDOF model.

\section{SDOF Systems}

2.1. Equivalent Analysis Method. In dynamical analysis, there are three important factors: work, strain energy, and kinetic energy. The work under external loading should be calculated by structural displacement. The structural strain energy is mainly caused by tensile strain, compressive strain, shear strain, and so on. The kinetic energy is also caused by the movement and rotation of mass block [22].

A structure can be replaced by an idealized system (dynamically equivalent), which shows almost the same time characteristics as the real structure. The distributed mass of a given structure is assigned to one or several concentrated masses, and the strain energy is assigned to one or several weightless and inelastic springs. In addition, the distributed loads are replaced by several concentrated loads on the concentrated mass. Therefore, this idealized equivalent system, which mainly consists of weightless springs, concentrated masses, and time-varying concentrated loads, is called a mass-spring-load dynamic equivalent system.

Although a basic structure has many degrees of freedom, a basic vibration mode plays a leading role under transitory loading. Therefore, it can be simplified to study an SDOF system that has the same characteristics and vibration modes as a real structure. The SDOF system is a simplified system with only one state of motion. Figure 1 shows the simplified system described using only one coordinate.

2.2. Equivalent System Transformation. The work under equivalent loads, strain energy, and kinetic energy in an equivalent system should be the same as the real structure and based on equal displacement and energy. Therefore, the structure can be equivalent to a mass-spring-load SDOF system, where the mass, resistance, and load are equivalent [23]. 


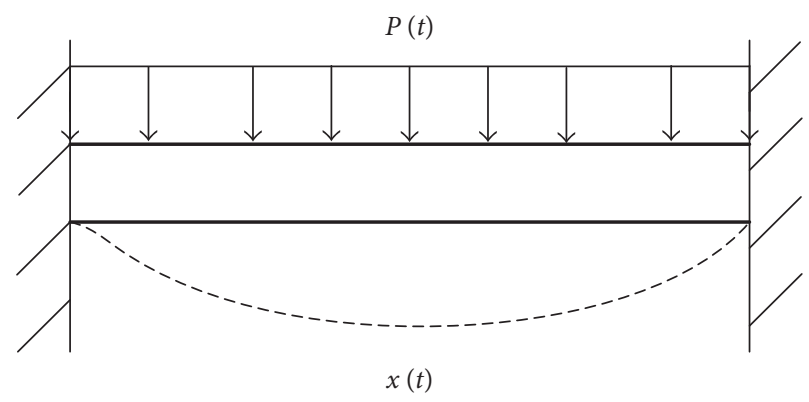

(a)

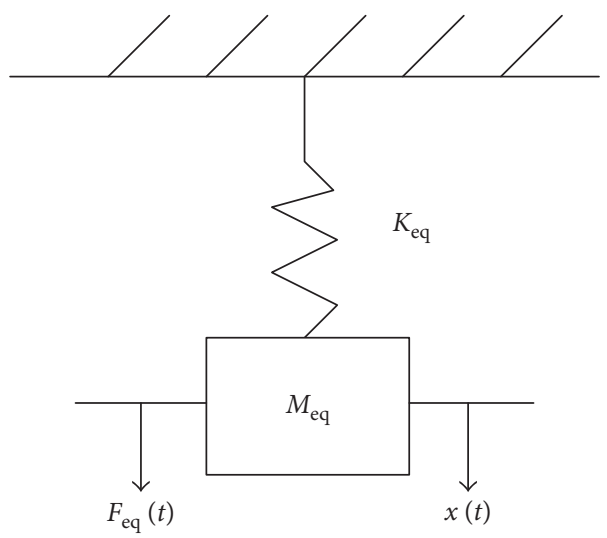

(b)

Figure 1: Equivalent single degree of freedom system: (a) real structure; (b) equivalent system.

2.2.1. Load Coefficient. The equivalent concentrated load is the total load on the structure, multiplied by the load coefficient, as shown in the following equation [22]:

$$
K_{\mathrm{L}}=\frac{F_{\mathrm{E}}}{F},
$$

where $F$ is the total load on the actual structure, $F_{\mathrm{E}}$ is the equivalent load, and $K_{\mathrm{L}}$ is the load coefficient. $F_{\mathrm{E}}$ follows the principle that work done by an equivalent load on an equivalent system is equal to that done by an actual load on an assumed deflection shape.

For a structure subjected to distributed loads,

$$
\begin{aligned}
\mathrm{WD} & =F_{\mathrm{E}} \cdot \delta_{\text {max }}=\int_{0}^{L} p(x) \delta(x) d x, \\
F_{\mathrm{E}} & =\int_{0}^{L} p(x) \varnothing(x) d x, \\
\varnothing(x) & =\frac{\delta(x)}{\delta_{\text {max }}},
\end{aligned}
$$

where WD is the work; $\delta_{\max }$ is the maximum structural deflection; $p(x)$ is the distributed loading on the structure; $\delta(x)$ is the deflection of any position; and $\varnothing(x)$ is the shape function, which is different in the elastic stage and plastic stage, so that $K_{\mathrm{L}}$ is different as well.

2.2.2. Mass Coefficient. The equivalent concentrated mass is the total distributed mass multiplied by the mass coefficient, which is shown as follows [22]:

$$
K_{\mathrm{M}}=\frac{M_{\mathrm{E}}}{M},
$$

where $M$ is the total mass on an actual structure, $M_{\mathrm{E}}$ is the equivalent mass, and $K_{\mathrm{M}}$ is the mass coefficient. $M_{\mathrm{E}}$ follows the principle that kinetic energy of an equivalent system is equal to that on the deflection shape of an actual structure.

For a continuous mass structure,

$$
\begin{aligned}
& \mathrm{KE}=\frac{1}{2} M_{\mathrm{E}}\left(\omega \delta_{\max }\right)^{2}=\frac{1}{2} \int_{0}^{L} m(x)[\omega \delta(x)]^{2} d x, \\
& M_{\mathrm{E}}=\int_{0}^{L} m(x) \varnothing^{2}(x) d x,
\end{aligned}
$$

where $\mathrm{KE}$ is the kinetic energy, $\omega$ is a natural vibration frequency, $m(x)$ is the distributed mass per unit length, and $\varnothing(x)$ is the shape function that is caused by external loads. $\varnothing(x)$ is different in the inelastic stage and plastic stage, so $K_{\mathrm{M}}$ is also different.

2.2.3. Resistance Coefficient. The equivalent resistance is the total resistance multiplied by the resistance coefficient, which is shown as follows [22]:

$$
K_{\mathrm{R}}=\frac{R_{\mathrm{E}}}{R}=\frac{K_{\mathrm{E}} \cdot \delta_{\text {max }}}{K \cdot \delta_{\text {max }}},
$$

where $R$ is the total resistance of an actual structure, $R_{\mathrm{E}}$ is the equivalent resistance, $K_{\mathrm{R}}$ is the resistance coefficient, $K_{\mathrm{E}}$ is the equivalent stiffness, and $K$ is the total stiffness of an actual structure. $R_{\mathrm{E}}$ follows the principle that strain energy of an actual structure under an assumed deflection is equal to that of an equivalent SDOF system. Because resistance of a structure is an internal force that restores the structure to its static position, $K_{\mathrm{R}}$ must be equal to $K_{\mathrm{L}}$.

2.2.4. Load-Mass Coefficient. The viscous damping force of a structure normally lags the inertia force by $1 / 4$ of a period under blast loading. The durations of blast loadings are only several milliseconds, so the blast loading rapidly disappears before the damping force appears. Therefore, it is not necessary to consider the damping force in an equation of motion, which is as follows [22]: 


$$
\begin{aligned}
M_{\mathrm{E}} \ddot{x}+K_{\mathrm{E}} x & =F_{\mathrm{E}}, \\
K_{\mathrm{M}} M \ddot{x}+K_{\mathrm{L}} K x & =K_{\mathrm{L}} F, \\
\frac{K_{\mathrm{M}}}{K_{\mathrm{L}}} M \ddot{x}+K x & =F, \\
K_{\mathrm{LM}} M \ddot{x}+K x & =F,
\end{aligned}
$$

where $K_{\mathrm{LM}}$ is the load-mass coefficient and $K_{\mathrm{LM}}=K_{\mathrm{M}} / K_{\mathrm{L}}$. Therefore, the transformation of the motion equation between the actual structure and equivalent system only needs one parameter, $K_{\mathrm{LM}}$.

The dynamic design factors for a cantilever support system in which one end is fixed and another end is a hinged joint are shown in Table 1.

2.3. Equivalent SDOF Model of an RC Pier. Liu [24, 25] and Tang $[26,27]$ have designed a round RC pier in Figure 2, for which essential design parameters are shown in Table 2 . The top of the pier is assumed a hinged constraint with two lateral displacements, and the bottom of the pier is assumed a fixed constraint. Therefore, the structural system of an RC pier is a cantilever support system.

Several assumptions must be made when the RC pier is simplified as an equivalent SDOF system under blast loading. (1) The RC pier can be simplified as an ideal rigid plastic member when only bending deformation is considered, ignoring shear deformation; (2) an ideal plastic hinge appears at the bottom and midheight of the pier when the $\mathrm{RC}$ pier experiences bending deformation; and (3) the pier is destroyed when the displacement at midheight reaches $X_{\mathrm{m}}$ [28].

The load and displacement at the midheight of the pier are shown in Figure 3(a) when the plastic hinge emerges at the bottom of the pier:

$$
\begin{aligned}
& P_{1}=\frac{8 M_{\mathrm{PE}}}{L^{2}} \\
& X_{1}=\frac{P_{1} L^{4}}{\left(185 E_{\mathrm{E}} I_{\mathrm{E}}\right)}=\frac{8 M_{\mathrm{PE}} L^{2}}{\left(185 E_{\mathrm{E}} I_{\mathrm{E}}\right)} .
\end{aligned}
$$

The additional load and displacement at the midheight of the pier are shown in Figure 3(b) when the plastic hinge emerges at the midheight of the pier:

$$
\begin{aligned}
P_{2} & =\frac{4 M_{\mathrm{PE}}}{L^{2}} \\
X_{2} & =\frac{5 P_{2} L^{4}}{\left(384 E_{\mathrm{E}} I_{\mathrm{E}}\right)}=\frac{20 M_{\mathrm{PE}} L^{2}}{\left(384 E_{\mathrm{E}} I_{\mathrm{E}}\right)} .
\end{aligned}
$$

\begin{tabular}{|c|c|c|c|c|}
\hline Sup & Stre & $K_{\mathrm{L}}$ & $K_{\mathrm{M}}$ & $K_{\mathrm{LM}}$ \\
\hline & & 0.58 & 0.45 & 0.78 \\
\hline & lasti & 0.64 & 0.50 & 0.78 \\
\hline & Plastic & 0.50 & 0.33 & 0.66 \\
\hline
\end{tabular}

The total load and displacement at the midheight of the pier are as follows when the pier becomes a geometrically unstable system:

$$
\begin{gathered}
P_{0}=P_{1}+P_{2}=\frac{12 M_{\mathrm{PE}}}{L^{2}}, \\
X_{0}=X_{1}+X_{2}=\frac{2 M_{\mathrm{PE}} L^{2}}{\left(21 E_{\mathrm{E}} I_{\mathrm{E}}\right)},
\end{gathered}
$$

TABLE 1: Dynamic design factors of the cantilever support system [22].

where $X_{1}$ is the displacement at the midheight of the pier when plastic hinge emerges at the bottom of the pier; $X_{2}$ is the additional displacement at the midheight of the pier when plastic hinge emerges at the midheight of the pier; $X_{0}$ is the total displacement when the pier becomes a geometrically unstable system; $M_{\mathrm{PE}}$ is the plastic limit bending moment of the pier, which is the same when plastic hinge emerges at the midheight and the bottom of the pier; $E_{\mathrm{E}}$ is the global equivalent elastic modulus of the pier; $I_{\mathrm{E}}$ is the global equivalent moment of inertia of the pier; $P_{1}$ is the horizontal pressure when plastic hinge emerges at the bottom of the pier; $P_{2}$ is the additional pressure when plastic hinge emerges at the bottom and midheight of the pier; and $P_{0}$ is the total pressure.

The equivalent simplified SDOF model of the pier ignoring the damping force can be deduced as follows:

$$
\begin{aligned}
M_{\mathrm{E}} \ddot{x}+K_{\mathrm{E}} x & =F_{\mathrm{E}}(t), \quad x<X_{\mathrm{E}}, \\
M_{\mathrm{E}} \ddot{x}+R_{\mathrm{E}} & =F_{\mathrm{E}}(t), \quad X_{\mathrm{E}}<x<X_{\mathrm{m}}, \\
X_{\mathrm{E}} & =\frac{5 L^{2} M_{\mathrm{PE}}}{\left(96 E_{\mathrm{E}} I_{\mathrm{E}}\right)},
\end{aligned}
$$

where $M_{\mathrm{E}}=K_{\mathrm{M}} M$, in which $M_{\mathrm{E}}$ is the equivalent mass of the RC pier, $M$ is the total mass of the RC pier, and $K_{\mathrm{M}}=0.5 ; K_{\mathrm{E}}=K_{\mathrm{L}} K_{0}$, in which $K_{\mathrm{E}}$ is the equivalent stiffness of the elastic stage and $K_{0}=307 E_{\mathrm{E}} I_{\mathrm{E}} / L^{3}, K_{0}$ is the equivalent initial stiffness, and $K_{L}=0.64 ; F_{\mathrm{E}}(t)=K_{L} F(t)$, where $F_{\mathrm{E}}(t)$ is the equivalent load, $F(t)=P(t) B L$, in which $B$ is the width of the pier and $L$ is the height of the pier; $R_{\mathrm{E}}=K_{L} R_{0}$, where $R_{\mathrm{E}}$ is the equivalent resistance extremum and $R_{0}=12 M_{\mathrm{PE}} / L^{2}$, in which $R_{0}$ is the initial limit resistance; $X_{\mathrm{E}}$ is the equivalent elastic displacement when the linear curve is equivalent to the ideal elastic-plastic curve; and $X_{\mathrm{m}}$ is the maximum plastic displacement. The resistance model of the RC pier is shown in Figure 4 [29].

\section{Blast Loading and Damage Failure Criterion}

3.1. Equivalent Blast Loading of an RC Pier. Blast loading on a structure is a complex loading and is related to the explosive position, explosive mass, structural shape, and surrounding environment. The blast type can be divided into a near-field explosion and a far-field explosion according to the explosive position and scale distance when explosive is located on the ground. The blast loading along the height of the pier can be assumed to be a trapezoidal distribution in the near-field explosion, which is examined in this paper. A simplified pressure distribution is shown in Figure 5, where the overpressure times at any height of the pier are considered to be equal, and the negative pressure of the blast 


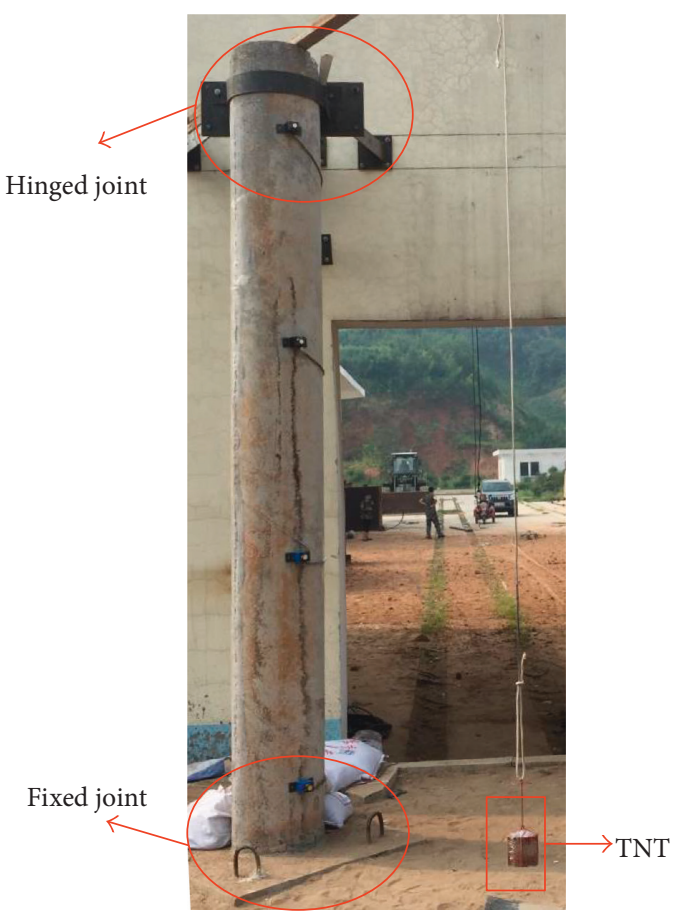

(a)

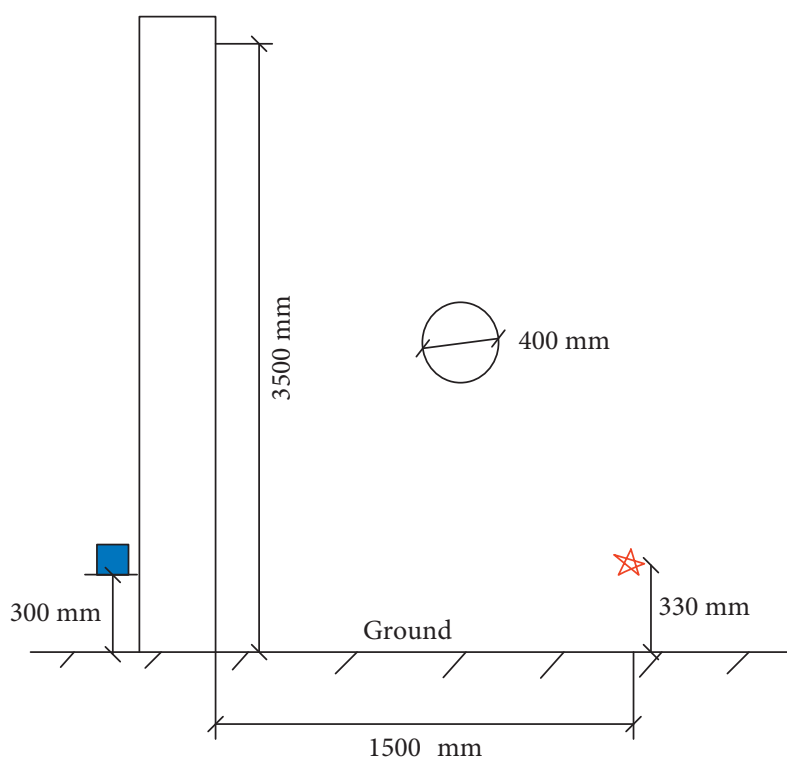

Accelerometer Explosive

FIGURE 2: RC pier experiment: (a) test specimen; (b) explosive location.

TABLe 2: Essential design parameters of the RC pier.

\begin{tabular}{lcccc}
\hline Specimen & Effective height & Diameter & Stirrup size & Yield strength of the stirrup \\
\hline RC pier & $3500 \mathrm{~mm}$ & $400 \mathrm{~mm}$ & $\varphi 8 \mathrm{~mm}$ & $300 \mathrm{MPa}$ \\
\hline Specimen & $\begin{array}{c}\text { Longitudinal } \\
\text { reinforcement size }\end{array}$ & Reinforcement ratio & $\begin{array}{c}\text { Yield strength of longitudinal } \\
\text { reinforcement }\end{array}$ & Concrete strength \\
\hline RC pier & $10 \varphi 12 \mathrm{~mm}$ & $0.9 \%$ & $400 \mathrm{MPa}$ & $40 \mathrm{MPa}$ \\
\hline
\end{tabular}

shock wave is ignored, as it is negligible when compared to the positive pressure.

The blast loading can be equivalent in accordance with the impulse equivalence on the structure. First, the peak pressure of equivalent uniform loading can be obtained from the following equation:

$$
\bar{P}=\frac{1}{2}\left(P_{1 \max }+P_{2 \max }\right) .
$$

Then, the equivalent duration of blast loading can be deduced from the duration of blast loading in the center of the pier, so the impulse of an equivalent uniform load can be calculated as

$$
t_{\mathrm{d}}=\frac{2 I}{\bar{P}}
$$

The blast loading history in the real pressure-time function can be simplified to the triangular blast loading in Figure 5(c), as shown in the following equation:

$$
\begin{aligned}
& P(t)=P_{\max }\left(1-\frac{t}{t_{\mathrm{d}}}\right), \quad 0<t<t_{\mathrm{d}}, \\
& P(t)=0, \quad t_{\mathrm{d}}<t,
\end{aligned}
$$

where $P_{\max }$ is the reflected overpressure peak of the blast shock wave and $t_{\mathrm{d}}$ is the duration of the simplified triangular blast loading.

3.2. Damage Failure Criteria of an RC Pier. It is assumed that the RC pier only experiences flexural failure under blast loading, as the maximum ductile deformation usually occurs at the midheight of the pier. Then, the damage extent of the RC pier can be evaluated according to the TM5-1300 manual [17]. The bearing angle of the pier and the ratio of maximum deflection at midheight to half height are usually an indicator of the flexural failure criterion of the pier. The flexural failure criterion of an $\mathrm{RC}$ pier is shown in Table 3.

It can be concluded from the above criterion that the reinforcement has yielded, but the concrete in the compression zone has not yet been destroyed when the bearing angle is $0^{\circ} \sim 2^{\circ}$. The concrete outside the compression reinforcement is crushed when the bearing angle is greater than $2^{\circ}$, leading to the compressive stress of concrete being transferred to the reinforced bar, causing the strength of the pier to decease. The concrete on both sides spalls when the 


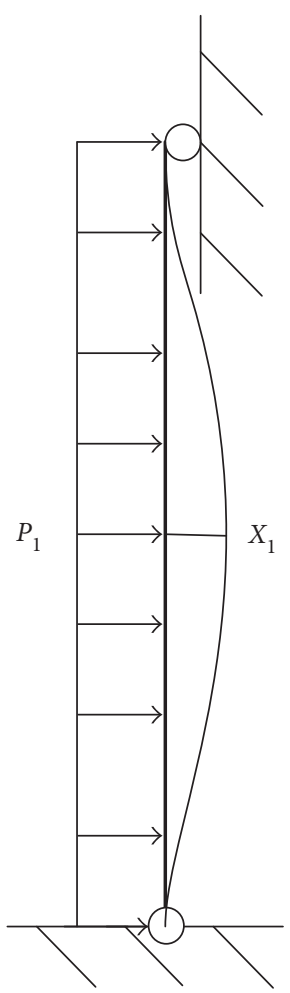

(a)

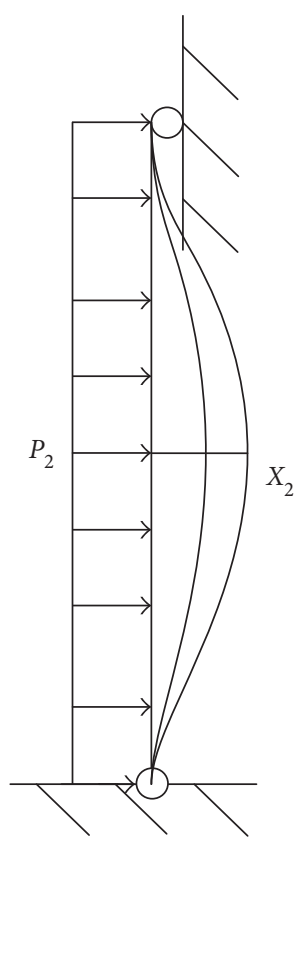

(b)

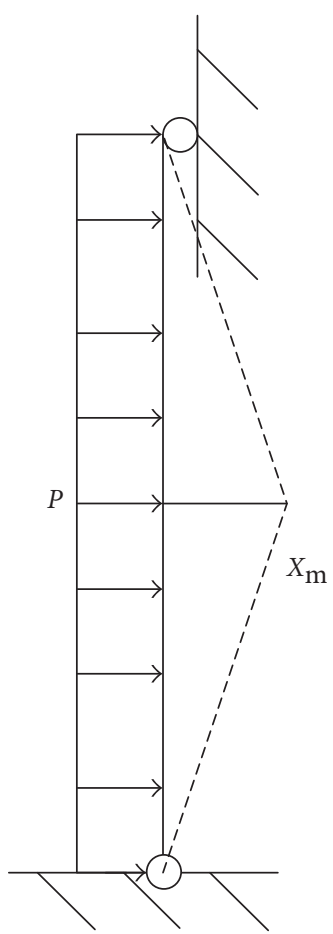

(c)

Figure 3: The simplified rigid plastic model of the RC pier: (a) plastic hinge at the bottom of the pier; (b) plastic hinge at the bottom and midheight of the pier; (c) simplified rigid plastic model.

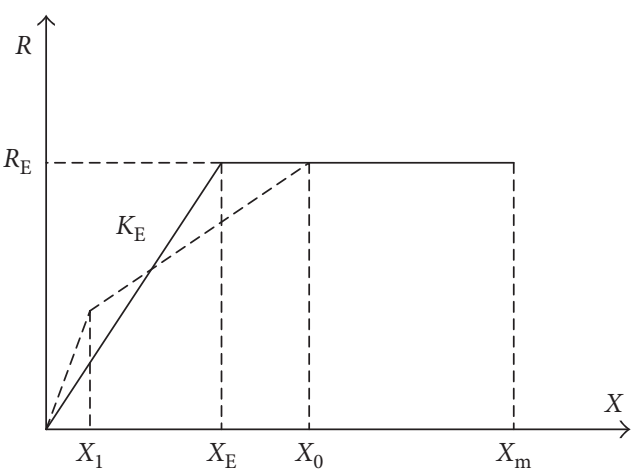

FIGURE 4: Resistance model [29].

bearing angle is greater than $5^{\circ}$, causing the overall bearing capacity to decrease. The reinforcement in the tension zone yields, or the concrete in the compression zone is crushed completely when the bearing angle is greater than $12^{\circ}$, meaning the pier collapses.

\section{P-I Curves}

4.1. Relations between Loads and Resistance. The structure itself has a natural vibration period. This vibration is related to the load and structure. The blast loading can be divided into impulse loading, pressure-impulse loading, and pressure loading according to the P-I curve, so that there are three different relationships between blast loading and resistance, as shown in Table 4. From the first curve, the time of maximum deflection is longer than the loading time $\left(t_{\mathrm{m}} / t_{0}>3\right)$, so the impulse loading causes structural destruction. From the third curve, the time of maximum deflection is shorter than the loading time $\left(0.1>t_{\mathrm{m}} / t_{0}\right)$, so the pressure loading causes structural destruction. However, when $3>t_{\mathrm{m}} / t_{0}>0.1$, both the pressure loading and impulse loading cause structural destruction.

4.2. The Characteristics of P-I Curves. Figure 6 shows the classic $P-I$ curve diagram, in which each curve is representative of the same damage extent of the structure. There are two asymptotes: the pressure asymptote and the impulse asymptote, which define the critical values of overpressure and impulse, respectively. The impulse asymptote physically shows the minimum impulse when the pier experiences some damage extent under blast loading. Moreover, the pressure asymptote physically shows the minimum pressure when the pier experiences some damage extent under blast loading.

The diagram is divided into two parts according to the $P-I$ curve: zone A and zone $\mathrm{B}$. When the blast loading is in zone $\mathrm{A}$, the actual structural damage extent is more significant than what is stated by the $P$-I curve. When the blast loading is in zone $\mathrm{B}$, the actual structural damage extent is less than what is stated by the $P-I$ curve. There are a series of $P$ - $I$ curves in a structural damage extent diagram, where each 


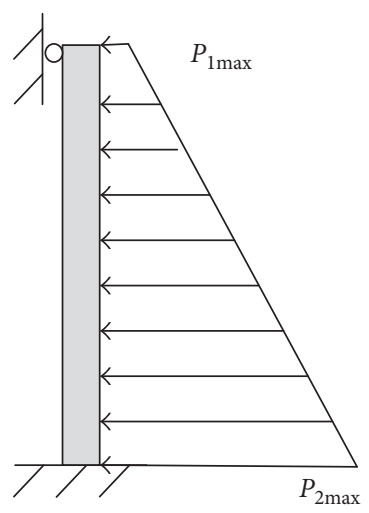

(a)

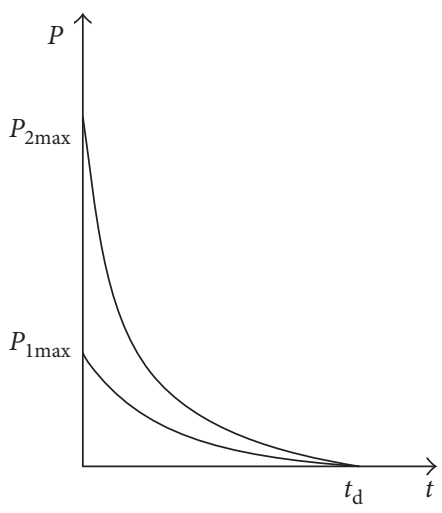

(b)

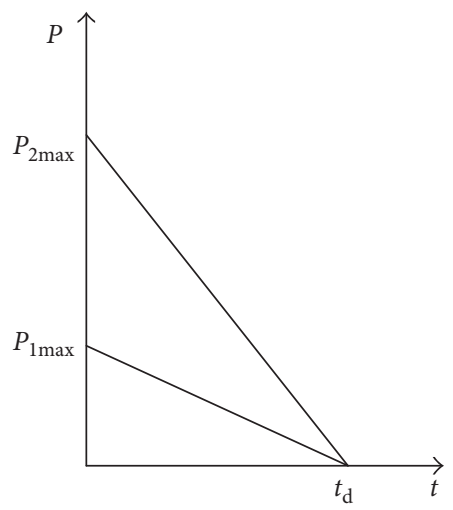

(c)

Figure 5: Simplified pressure distribution: (a) trapezoidal load distribution; (b) real pressure history; (c) simplified pressure history.

TABLE 3: The failure criterion of an RC pier.

\begin{tabular}{|c|c|c|c|c|}
\hline Index & Slight damage & Moderate damage & Severe damage & Collapse \\
\hline Bearing angle $\left({ }^{\circ}\right)$ & $0 \sim 2$ & $2 \sim 5$ & $5 \sim 12$ & $>12$ \\
\hline Maximum lateral displacement $(\mathrm{mm})$ & $0 \sim 61$ & $61 \sim 153$ & $153 \sim 364$ & $>364$ \\
\hline
\end{tabular}

TABLE 4: Load-resistance history.

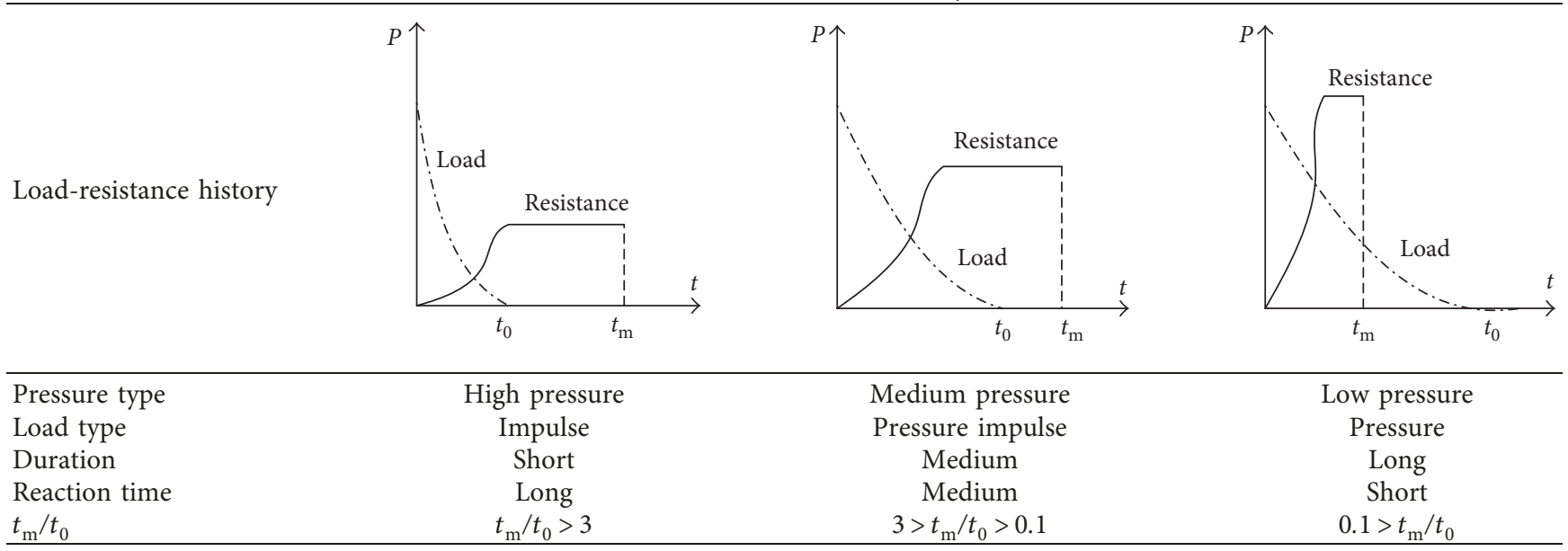

Note. $t_{\mathrm{m}}$ is the time of maximum deflection and $t_{0}$ is the loading time.

curve corresponds to a different damage extent. However, the damage extent of a structure can be distinguished between different curves, which are defined as slight damage, moderate damage, severe damage, and failure.

4.3. P-I Curves of an RC Pier. To determine the $P$ - I curve of the pier, the blast loading on the structure must follow the above assumptions. Then, the $P-I$ curves of an experimental RC pier can be drawn according to the above failure criteria when the top of the pier produces $2^{\circ}, 5^{\circ}$, and $12^{\circ}$ angular displacements, which are shown in Figure 7.

From Figure 7, the coordinate system is divided into four parts by three damage curves. The pier experiences slight damage when the value is below the $\theta=2^{\circ}$ curve, and the pier experiences moderate damage when the value is between the $\theta=2^{\circ}$ curve and the $\theta=5^{\circ}$ curve. The pier experiences severe damage when the value is between the $\theta=5^{\circ}$ curve and the $\theta=12^{\circ}$ curve, and finally, the pier collapses and fails when the value is above the $\theta=12^{\circ}$ curve. Three equal damage lines are fitted and shown in the following equations:

$$
\begin{gathered}
(P-0.66)(I-2.35)^{1.5}=0.08616 \\
(P-1.70)(I-5.95)^{1.5}=0.08870 \\
(P-3.20)(I-14.35)^{1.5}=0.20841 .
\end{gathered}
$$

From the abovementioned equations, the corresponding pressure asymptotes are $0.66 \mathrm{MPa}, 1.70 \mathrm{MPa}$, and $3.2 \mathrm{MPa}$ when the top of the pier produces $2^{\circ}, 5^{\circ}$, and $12^{\circ}$ angular displacements, respectively. In other words, the minimum overpressures are $0.66 \mathrm{MPa}, 1.70 \mathrm{MPa}$, and $3.2 \mathrm{MPa}$ when 


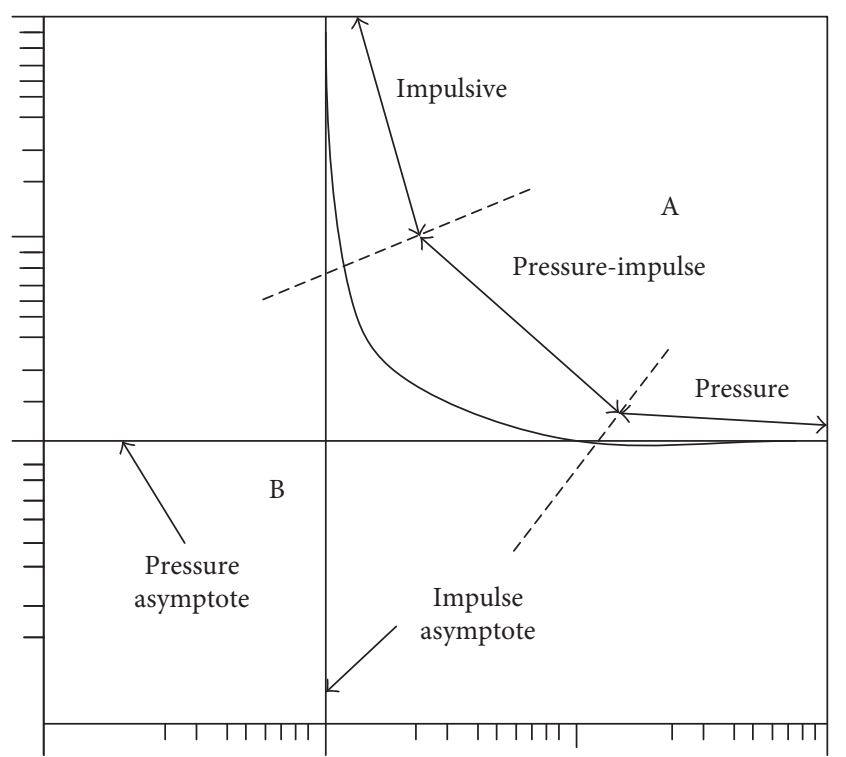

Figure 6: Typical $P$ - $I$ curve diagram.

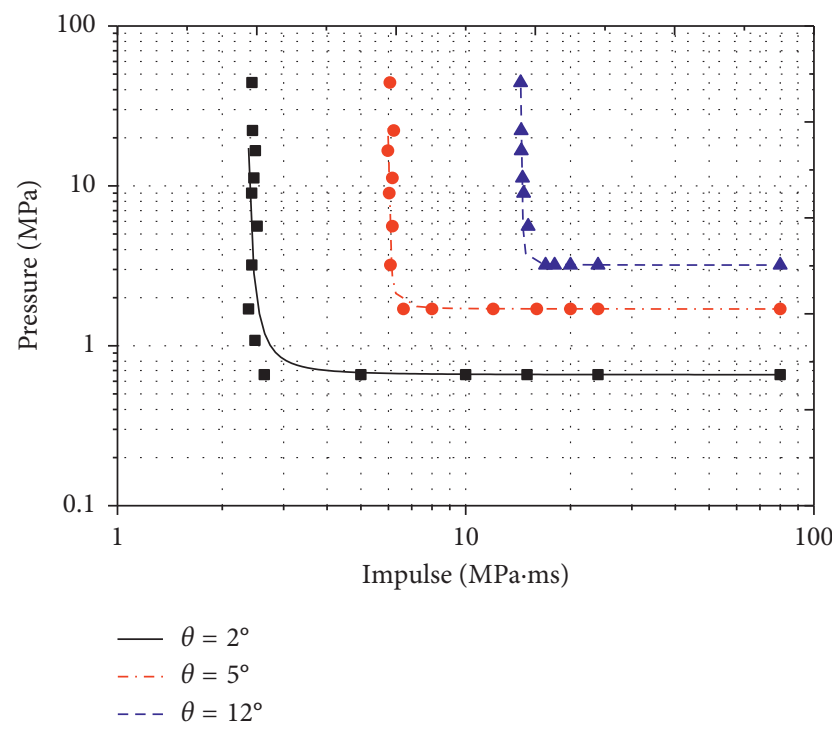

Figure 7: Calculated data and fitting $P-I$ curves.

the RC pier experience slight damage, moderate damage, and severe damage, respectively.

The corresponding impulse asymptotes are $2.35 \mathrm{MPa} \cdot \mathrm{ms}$, $5.95 \mathrm{MPa} \cdot \mathrm{ms}$, and $14.35 \mathrm{MPa} \cdot \mathrm{ms}$ when the top of the pier produces $2^{\circ}, 5^{\circ}$, and $12^{\circ}$ angular displacements, respectively. In other words, the minimum impulses are $2.35 \mathrm{MPa} \cdot \mathrm{ms}$, $5.95 \mathrm{MPa} \cdot \mathrm{ms}$, and $14.35 \mathrm{MPa} \cdot \mathrm{ms}$ when the RC pier experiences slight damage, moderate damage, and severe damage, respectively.

From the diagram, the curved section of the P-I curve is relatively short, implying that it is more difficult to produce flexural shear failure than flexural failure and shear failure.

Once the $P$ - $I$ curves of the RC pier are determined, the damage extent of the RC pier can be quickly evaluated by the overpressure and impulse.

\section{Numerical Verification}

5.1. Geometric Model. To study the validity of above computational method and the accuracy of $P$ - I curves, numerical simulation is the most common and effective method [30]. In this paper, ANSYS/LS-DYNA, dynamic explicit analysis software, is used to build a finite element model of an RC pier, which is shown in Figure 8. The diameter of circular cross section is $400 \mathrm{~mm}$, and the effective height of the pier is $3500 \mathrm{~mm}$. Other geometric parameters are set according to the experimental pier. In this model, concrete is simulated by 8 -noded solid164 element, and steel bars are simulated by 2 -noded beam 161 element, whose mesh size is $20 \mathrm{~mm}$. The number of concrete elements is 55500, and the number of steel bar elements is 3030 . The bottom of the pier is set as a fixed constraint, and the top of the pier is set as a hinged constraint. Different elements are coupled with common nodes ignoring relative slippage due to a fairly short explosion time.

5.2. Material Model. The concrete uses the material model *MAT_CONCRETE_DAMAGE_REL3, called the K\&C model, which mainly analyzes the dynamical response of the concrete structure under blast loading [31]. The model is the modified pseudotensor concrete material, including three independent failure surfaces, damage effects, and strain rate effects to control complex mechanical properties [32]. The failure criterion of this model is determined by initial yield failure surface, maximum strength failure surface, and residual strength failure surface, whose three invalid compression meridians consist of eight independent parameters. The compression meridian formulas are as follows:

$$
\begin{gathered}
\Delta \sigma_{\mathrm{y}}=a_{\mathrm{oy}}+\frac{P}{\left(a_{1 \mathrm{y}}+a_{2 \mathrm{y}} P\right)}, \\
\Delta \sigma_{\mathrm{m}}=a_{\mathrm{o}}+\frac{P}{\left(a_{1}+a_{2} P\right)}, \\
\Delta \sigma_{\mathrm{r}}=\frac{P}{\left(a_{1 \mathrm{f}}+a_{2 \mathrm{f}} P\right)},
\end{gathered}
$$

where $\Delta \sigma_{\mathrm{y}}$ is the equivalent yield strength; $\Delta \sigma_{\mathrm{m}}$ is the equivalent failure strength; $\Delta \sigma_{\mathrm{r}}$ is the equivalent residual strength; $a_{\mathrm{oy}}, a_{1 \mathrm{y}}, a_{2 \mathrm{y}}, a_{\mathrm{o}}, a_{1}, a_{2}, a_{1 \mathrm{f}}$, and $a_{2 \mathrm{f}}$ are the material constant determined by the unconfined compression test and three axial compression test; $P$ is the hydrostatic pressure. The specific function relation of failure surface under different stress states are as follows:

$$
\begin{gathered}
\Delta \sigma_{\mathrm{r}}=\eta \Delta \sigma_{\mathrm{m}}+(1-\eta) \Delta \sigma_{\mathrm{y}}\left(\lambda \leq \lambda_{n}\right), \\
\Delta \sigma_{\mathrm{h}}=\eta \Delta \sigma_{\mathrm{m}}+(1-\eta) \Delta \sigma_{\mathrm{y}}\left(\lambda \geq \lambda_{n}\right),
\end{gathered}
$$

where $\lambda$ is the damage variable that is function of the equivalent plastic strain, $\lambda_{\mathrm{n}}$ is the damage turning point between strengthening phase and softening phase, and $\eta$ is the function of the damage value that ranges from zero to one. 


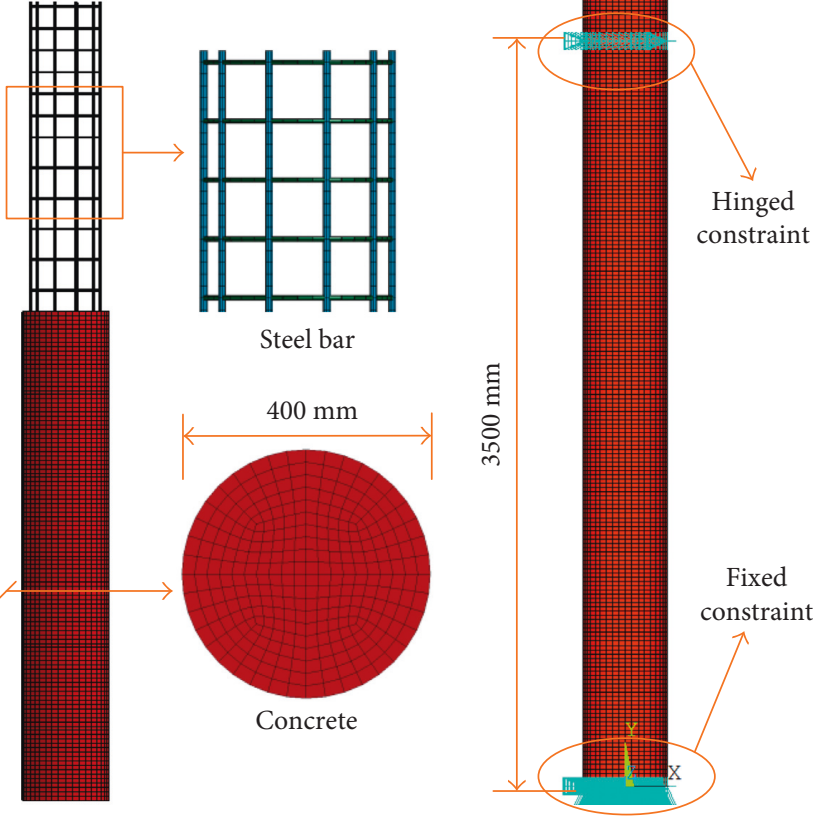

Figure 8: Finite element model of an RC pier.

$\mathrm{K} \& \mathrm{C}$ model also considers the damage effects including shear deformation damage and volume damage under three-direction stretching. The damage variables are as follows:

$$
\begin{aligned}
& \lambda=\int_{0}^{\overline{\varepsilon^{\mathrm{P}}}} \frac{\overline{d \varepsilon^{\mathrm{P}}}}{r_{\mathrm{f}}\left(1+P / \mathrm{r}_{\mathrm{f}} \mathrm{f}_{\mathrm{t}}\right)^{b_{1}}}, \quad P \geq 0, \\
& \lambda=\int_{0}^{\overline{\varepsilon^{\bar{P}}}} \frac{\overline{d \varepsilon^{\mathrm{P}}}}{r_{\mathrm{f}}\left(1+P / \mathrm{r}_{\mathrm{f}} \mathrm{f}_{\mathrm{t}}\right)^{b_{2}}}, \quad P \geq 0, \\
& \lambda=b_{3} f_{\mathrm{d}} k_{\mathrm{d}}\left(\varepsilon_{\mathrm{V}}-\varepsilon_{\mathrm{V}, \text { yield }}\right),
\end{aligned}
$$

where $r_{\mathrm{f}}$ is the coefficient of the strain rate effect, $b_{1}$ is the damage effect under compression, $b_{2}$ is the damage effect under tension, $b_{3}$ is the damage effect under volume stretching, $\overline{d \varepsilon^{\mathrm{P}}}$ is the equivalent plastic strain increment, $f_{\mathrm{d}}$ is the stress limiting factor, $k_{\mathrm{d}}$ is the internal variable factor, $\varepsilon_{\mathrm{V}}$ is the volumetric strain, and $\varepsilon_{\mathrm{V} \text {,yield }}$ is the volumetric strain at the yield point.

This model is a strain rate-related materials whose strength is increased by the strain rate versus increasing factor of strain rate. Therefore, the increasing function is as follows:

$$
\Delta \sigma_{\mathrm{e}}=r_{\mathrm{f}} \Delta\left(\frac{P}{r_{\mathrm{f}}}\right)
$$

where $r_{\mathrm{f}}$ is the coefficient of the strain rate effect and $P$ is the hydrostatic pressure.

However, this complicated concrete constitutive has been embedded into LS-DYNA software; therefore, only density, passion ratio, uniaxial compressive strength, and dynamic increase factor are input into software, and other parameters are generated automatically. In this paper, the strain rate effect of concrete modes comes from the modified models. The DIFs [33] of concrete tension strength are seen in the following equations:

$$
\begin{aligned}
& \text { TDIF }=\frac{f_{\text {td }}}{f_{\mathrm{ts}}}=0.26\left(\lg \dot{\varepsilon}_{d}\right)+2.06, \quad \dot{\varepsilon}_{d} \leq 1 / \mathrm{s}, \\
& \mathrm{TDIF}=\frac{f_{\mathrm{td}}}{f_{\mathrm{ts}}}=2\left(\lg \dot{\varepsilon}_{d}\right)+2.06, \quad 1 / \mathrm{s}<\dot{\varepsilon}_{d} \leq 2 / \mathrm{s}, \\
& \mathrm{TDIF}=\frac{f_{\mathrm{td}}}{f_{\mathrm{ts}}}=1.44331\left(\lg \dot{\varepsilon}_{d}\right)+2.22766, \quad 2 / \mathrm{s}<\dot{\varepsilon}_{d} \leq 150 / \mathrm{s},
\end{aligned}
$$

where $f_{\text {td }}$ is the dynamic tension strength of concrete at the strain rate of $\dot{\varepsilon}_{\mathrm{d}}$ and $f_{\mathrm{ts}}$ is the static tension strength of concrete at the strain rate of $\dot{\varepsilon}_{\mathrm{ts}}\left(\dot{\varepsilon}_{\mathrm{ts}}=10^{-6} / \mathrm{s}\right)$.

The DIFs of concrete compressive strength [31] are seen in the following equations:

$$
\begin{aligned}
& \mathrm{CDIF}=\frac{f_{\mathrm{cd}}}{f_{\mathrm{cs}}}=0.0419\left(\lg \dot{\varepsilon}_{\mathrm{d}}\right)+1.2165, \quad \dot{\varepsilon}_{\mathrm{d}} \leq 30 / \mathrm{s}, \\
& \mathrm{CDIF}=\frac{f_{\mathrm{cd}}}{f_{\mathrm{cs}}}=0.8988\left(\lg \dot{\varepsilon}_{\mathrm{d}}\right)^{2}-2.8255\left(\lg \dot{\varepsilon}_{\mathrm{d}}\right)+3.4907,
\end{aligned}
$$

$$
\dot{\varepsilon}_{\mathrm{d}}>30 / \mathrm{s} \text {. }
$$

The steel bar uses material model *MAT_PLASTIC_KINEMATIC, called the plasticity kinematic model, which uses the Cowper-Symonds model to consider the dynamic constitutive relationship [34]. This model consists of the isotropy and kinematic hardening model related with strain rate and can consider material failure. Cowper-Symonds model can be defined as following equation:

$$
\sigma_{\mathrm{Y}}=\left[1+\left(\frac{\dot{\varepsilon}}{C}\right)^{1 / \mathrm{p}}\right]\left(\sigma_{0}+\beta E_{\mathrm{p}} \varepsilon_{\mathrm{p}}^{\text {eff }}\right),
$$

where $\sigma_{0}$ is the initial yield stress, $\dot{\varepsilon}$ is the strain rate, $C$ and $p$ are the strain rate parameter of the C-S model, $\varepsilon_{\mathrm{p}}^{\text {eff }}$ is the effective plastic strain, and $\beta$ is the hardening parameter consisting of 0 (only kinematic hardening) and 1 (only isotropic hardening). $E_{\mathrm{p}}$ is the plastic hardening modulus and $E_{\tan }$ is the tangent modulus, which are related as follows:

$$
E_{\mathrm{p}}=\frac{E_{\mathrm{tan}} E}{E-E_{\tan }} .
$$

In this paper, the DIF [34] of the steel bar is as follows:

$$
\mathrm{DIF}=\left(\frac{\dot{\varepsilon}}{10^{-4}}\right)^{\alpha}, \quad \alpha=0.074-0.04 \frac{f_{\mathrm{y}}}{414},
$$

where $\dot{\varepsilon}$ is the strain rate of reinforcement, $f_{\mathrm{y}}$ is the yield strength, and the application ranges are $10^{-4} \mathrm{~s}^{-1} \leq$ $\dot{\varepsilon} \leq 255 \mathrm{~s}^{-1}$ and $270 \mathrm{MPa} \leq f_{\mathrm{y}} \leq 710 \mathrm{MPa}$.

The DIFs of concrete and the steel bar are shown in Figure 9. The material parameters are mainly in Table 5. 


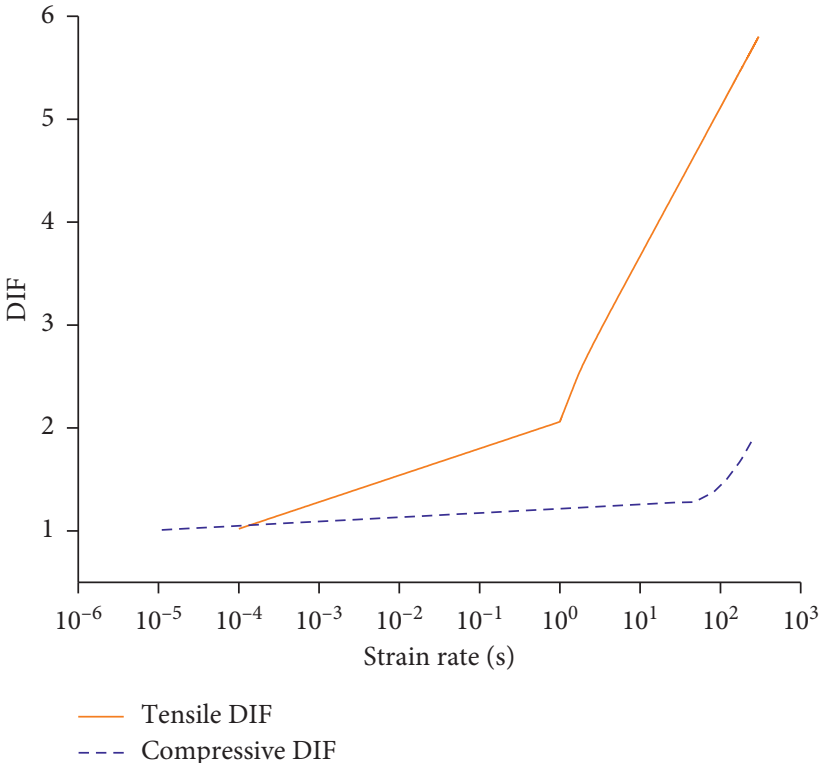

(a)

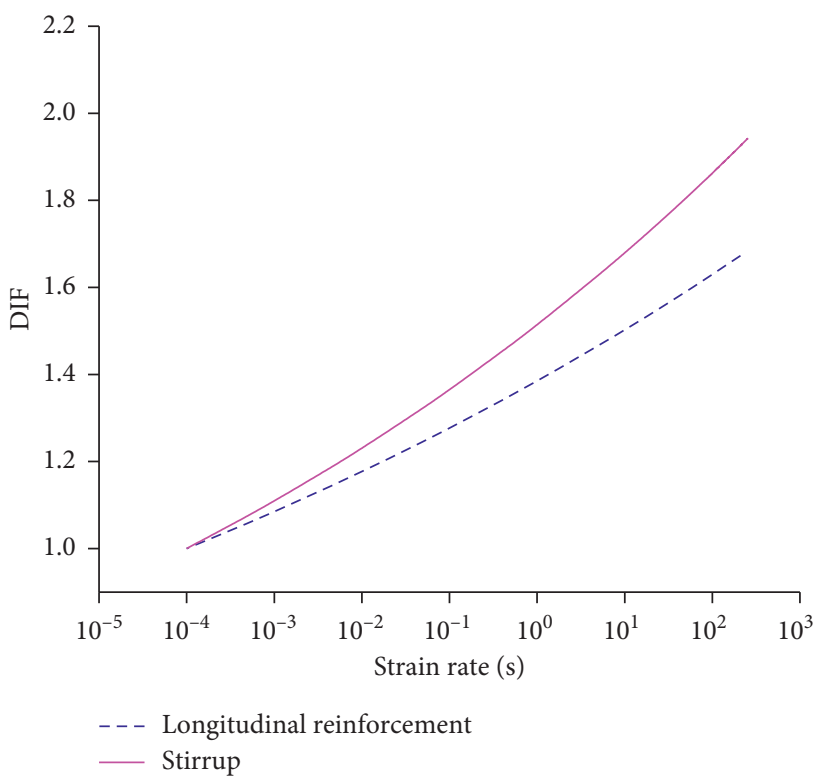

(b)

FIGURE 9: DIF of concrete (a) and steel bar (b).

TABLE 5: Material parameters.

\begin{tabular}{|c|c|c|c|}
\hline *MAT_CONCRETE_DAMAGE_REL3 & $\begin{array}{c}\text { Material number } \\
\text { Density } \\
\text { Poisson ratio } \\
\text { Unconfined compressive strength }\end{array}$ & $\begin{array}{r}\mathrm{C} \\
2.5 \times \\
4.0\end{array}$ & $\begin{array}{l}\mathrm{e} \\
\mathrm{Pa}\end{array}$ \\
\hline *MAT_PIECEWISE_LINEAR_PLASTICITY & $\begin{array}{l}\text { Material number } \\
\text { Yield strength } \\
\text { Density } \\
\text { Elastic modulus } \\
\text { Poisson ratio } \\
\text { Tangent modulus } \\
\text { Failure strain }\end{array}$ & $\begin{array}{c}\text { Longitudinal bar } \\
2 \\
4.0 \times 10^{8} \mathrm{~Pa} \\
7.85 \times 10^{3} \mathrm{~kg} / \mathrm{m}^{3} \\
2.0 \times 10^{11} \mathrm{~Pa} \\
0.3 \\
2.0 \times 10^{9} \mathrm{~Pa} \\
0.15\end{array}$ & $\begin{array}{c}\text { Stirrup } \\
3 \\
3.0 \times 10^{8} \mathrm{~Pa} \\
7.85 \times 10^{3} \mathrm{~kg} / \mathrm{m}^{3} \\
2.0 \times 10^{11} \mathrm{~Pa} \\
0.3 \\
2.0 \times 10^{9} \mathrm{~Pa} \\
0.15\end{array}$ \\
\hline
\end{tabular}

5.3. Blast Loading. There are three methods to apply blast loading on the bridge pier. The first one is fluid-solid coupling [35] that mainly builds air and explosive element to simulate propagation of the shock wave and interaction between the shock wave and structure by some keywords, which is a direct research method; however, its computational efficiency is very low. The second one is ConWep methods [36] that applies blast loading from a conventional weapon on the structure, which only considers explosive location, explosive equivalent, detonating time, and explosive type; however, it only supply two shock waves with incident angle, namely, free-field spherical shock wave and hemispherical shock wave. The third one used in this paper is simplified blast loading (Figure 10) that simplifies traditional pressure history to triangle loading in time domain. In dynamics, the loading can be equivalent to impulse loading when the natural vibration period of the structure is more than five times as long as the duration of loading. The duration of blast loading is normally millisecond and far below the natural vibration period of the structure; therefore, this model can be used to simulate blast loading reasonably. This method has high computational efficiency, simple model, and clear physical concepts.

According to the above research and hypothesis, blast loading distributed on the vertical pier is also triangle distribution on the front face due to explosive detonating at the bottom of the pier. Then, blast loading distributed on the lateral pier for circular cross section can be simplified as uniform loading shown in Figure 10, which proves to be effective. This FE model has been verified according to the explosion test in [20]; therefore, it can be used to calculate other explosive cases.

5.4. Displacement Analysis. LS-DYNA software is a program package for nonlinear explicit analysis, including geometric nonlinearity, material nonlinearity, and interfacial state 


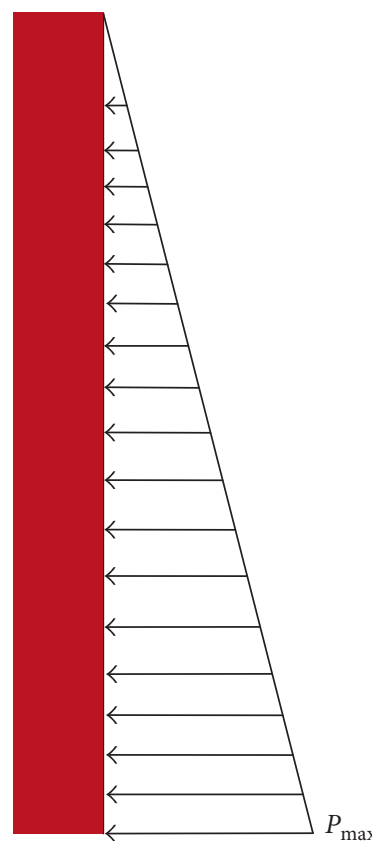

Vertical distribution
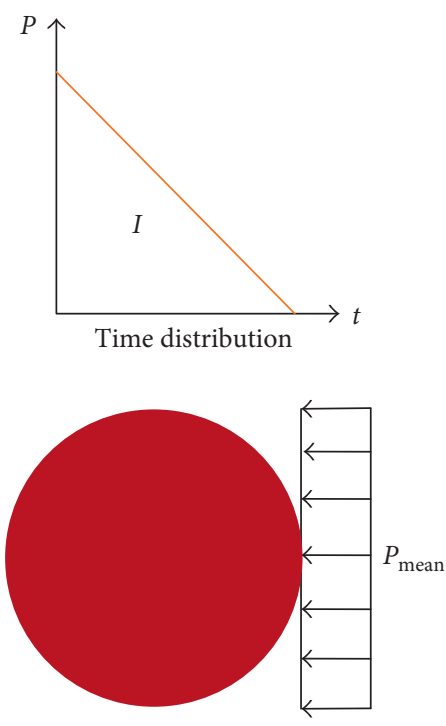

Lateral distribution
Figure 10: Blast loading model on the bridge pier.

nonlinearity such as friction and contact. Although the calculation of blast loading has been simplified, it will still take a large number of time to compute each case. In addition, the postexplosive assessment of the structure by numerical simulation is still accurate. But numerical simulation is too convenient to apply for engineers. Therefore, it is necessary to validate the above theoretical analysis by numerical simulation in this paper to evaluate the postexplosive damage rapidly by the $P$ - $I$ curve for engineers.

There are three points selected separately on different $P-I$ curves, so there are nine overpressures and nine impulses. Each set of overpressure and impulse are loaded on the simulative model, and displacements in the middle of the pier are calculated in Table 6. All numerical displacements are less than the theoretical displacements, but all the errors are less than $20 \%$. Therefore, theoretical displacements and numerical displacements are in good agreement. A simplified theoretical analysis can effectively evaluate the damage of the pier, so that it can supply a rapid and effective assessment method for engineers.

\section{Conclusions}

Based on the equivalent SDOF method in this paper, the damage extent of an RC pier is studied under blast loading, and the main conclusions are as follows:

(a) The RC pier can be simplified as the equivalent SDOF system based on energy equality, and the blast loading can be simplified as a uniform distribution so that the computation time is greatly reduced. According to this method, the dynamic response and damage extent of the pier can be evaluated quickly. Therefore, this method can be applied to practical engineering.
TABLE 6: Displacement comparison.

\begin{tabular}{cccccc}
\hline & $\begin{array}{c}\text { Theoretical } \\
\text { displacement } \\
(\mathrm{mm})\end{array}$ & $\begin{array}{c}P \\
(\mathrm{MPa})\end{array}$ & $\begin{array}{c}I \\
(\mathrm{MPa} \cdot \mathrm{ms})\end{array}$ & $\begin{array}{c}\text { Numerical } \\
\text { displacement } \\
(\mathrm{mm})\end{array}$ & $\begin{array}{c}\text { Error } \\
(\%)\end{array}$ \\
\hline \multirow{2}{*}{$2^{\circ}$} & \multirow{3}{*}{61.0} & 10.00 & 2.39 & 59.8 & 1.97 \\
& & 0.66 & 30.00 & 50.5 & 17.21 \\
& & 0.82 & 3.00 & 52.5 & 13.93 \\
\hline \multirow{2}{*}{$5^{\circ}$} & 153.0 & 5.00 & 6.04 & 141.0 & 7.84 \\
& & 1.70 & 30.00 & 136.0 & 11.11 \\
& & 1.73 & 8.00 & 123.0 & 19.60 \\
\hline \multirow{3}{*}{$12^{\circ}$} & 364.0 & 10.00 & 14.45 & 329.0 & 9.62 \\
& & 3.20 & 30.00 & 319.0 & 12.36 \\
& & 3.22 & 20.00 & 311.0 & 14.56 \\
\hline
\end{tabular}

Error $=($ theoretical $\quad$ displacement - numerical $\quad$ displacement $) /$ theoretical displacement $\times 100 \%$.

(b) Based on the SDOF systems and the uniform explosive load, the $P-I$ curves and corresponding fitting formulas of the RC pier are obtained. The minimum overpressures are $0.66 \mathrm{MPa}, 1.70 \mathrm{MPa}$, and $3.20 \mathrm{MPa}$ when the RC pier experiences slight damage, moderate damage, and severe damage, respectively, and the minimum impulses are $2.35 \mathrm{MPa} \cdot \mathrm{ms}, 5.95 \mathrm{MPa} \cdot \mathrm{ms}$, and $14.35 \mathrm{MPa} \cdot \mathrm{ms}$ when the RC pier experiences slight damage, moderate damage, and severe damage, respectively. The damage extent of the RC pier in the case of any overpressure and impulse can be quickly evaluated through the $P$-I curves.

(c) Through the numerical simulation verification, the midspan displacements calculated by the simplified method and the midspan numerical displacements are in good agreement. The damage extent obtained by the simplified method and the damage extent obtained by numerical simulation are also in good agreement. Therefore, P-I curves based on the simplified method can used to effectively evaluate the damage extent of an RC pier, which can supply a rapid and effective assessment for engineers.

\section{Data Availability}

The data used to support the findings of this study are available from the corresponding author upon request.

\section{Conflicts of Interest}

The authors declare that there are no conflicts of interest regarding the publication of this paper.

\section{Acknowledgments}

This work was supported by the National Key Research and Development Program of China (Grant no. 2017YFC0703405), the National Nature Science Foundation of China (Grant no. 51678141), the Fund of State Key Laboratory of Bridge Engineering Structural Dynamics, and the Key Laboratory of Bridge Earthquake Resistance Technology, Ministry of Communications, PRC (201801). 


\section{References}

[1] W. Wang, R. C. Liu, and B. Wu, "Analysis of a bridge collapsed by an accidental blast loads," Engineering Failure Analysis, vol. 36, pp. 353-361, 2014.

[2] A. K. M. Anwarul Islam and N. Yazdani, "Blast capacity and protection of AASHTO girder bridges," in Proceedings of the 4th Forensic Congress, ASCE, Reston, VA, USA, 2006.

[3] E. B. Williamson and D. Williams, "Prediction of airblast loads on bridge columns," in Proceedings of the 80th Shock and Vibration Symposium (SAVIAC), San Diego, CA, USA, 2009.

[4] D. E. Jarrett, "Derivation of the British explosives safety distances," Annals of the New York Academy of Sciences, vol. 152, no. 1, pp. 18-35, 1968.

[5] W. E. Baker, P. A. Cox, J. J. Kulesz, R. A. Strehlow, and P. S. Westine, Explosion Hazards and Evaluation, Vol. 5, Elsevier, Amsterdam, Netherlands, 2012.

[6] J. W. Wesevich and C. J. Oswald, "Empirical based concrete masonry pressure-impulse diagrams for varying degrees of damage," in Structures Congress, pp. 1-12, Metropolis and Beyond, New York, NY, USA, 2005.

[7] T. Krauthammer, S. Astarlioglu, J. Blasko, T. B. Soh, and P. H. Ng, "Pressure-impulse diagrams for the behavior assessment of structural components," International Journal of Impact Engineering, vol. 35, no. 8, pp. 771-783, 2008.

[8] J. Dragos, C. Wu, M. Haskett, and D. Oehlers, "Derivation of normalized pressure impulse curves for flexural ultra-high performance concrete slabs," Journal of Structural Engineering, vol. 139, no. 6, pp. 875-885, 2013.

[9] A. A. Mutalib and H. Hao, "Development of P-I diagrams for FRP strengthened RC columns," International Journal of Impact Engineering, vol. 38, no. 5, pp. 290-304, 2011.

[10] C. S. Shim, D. H. Shin, and N. R. Yun, "Pressure-impulse diagram of multi-layered aluminum foam panels under blast pressure," Journal of Engineering Science and Technology, vol. 8, no. 3, pp. 285-300, 2013.

[11] Y. C. Shi, H. Hao, and Z. X. Li, "Numerical derivation of pressure-impulse diagrams for prediction of RC column damage to blast loads," International Journal of Impact Engineering, vol. 35, no. 11, pp. 1213-1227, 2008.

[12] Q. M. Li and H. Meng, "Pressure-impulse diagram for blast loads based on dimensional analysis and single-degree-offreedom model," Journal of Engineering Mechanics, vol. 128, no. 1, pp. 87-92, 2002.

[13] A. S. Fallah and L. A. Louca, "Pressure-impulse diagrams for elastic-plastic-hardening and softening single-degree-offreedom models subjected to blast loading," International Journal of Impact Engineering, vol. 34, no. 4, pp. 823-842, 2007.

[14] G. W. Ma, H. J. Shi, and D. W. Shu, "P-I diagram method for combined failure modes of rigid-plastic beams," International Journal of Impact Engineering, vol. 34, no. 6, pp. 1081-1094, 2007.

[15] M. Colombo and P. Martinelli, "Pressure-impulse diagrams for RC and FRC circular plates under blast loads," European Journal of Environmental and Civil Engineering, vol. 16, no. 7, pp. 837-862, 2012.

[16] J. Dragos and C. Q. Wu, "A new general approach to derive normalized pressure impulse curves," International Journal of Impact Engineering, vol. 62, pp. 1-12, 2013.

[17] W. Wang, D. Zhang, F. Y. Lu, F. J. Tang, and S. C. Wang, "Pressure-impulse diagram with multiple failure modes of one-way reinforced concrete slab under blast loading using SDOF method," Journal of Central South University, vol. 20, no. 2, pp. 510-519, 2013.
[18] T. Krauthammer, "Blast-resistant structural concrete and steel connections," International Journal of Impact Engineering, vol. 22, no. 9, pp. 887-910, 1999.

[19] L. J. Malvar, K. B. Morrill, and J. E. Crawford, "Numerical modeling of concrete confined by fiber-reinforced composites," Journal of Composites for Construction, vol. 8, no. 4, pp. 315-322, 2004.

[20] C. H. Norris, Structural Design for Dynamic Loads, McGrawHill, New York, NY, USA, 1959.

[21] J. M. Biggs, Introduction to Structural Dynamics, McGrawHill, New York, NY, USA, 1964.

[22] USA Department of the Army, Structures to Resist the Effects of Accidental Explosion, vol. 88, no. 22, Department of the Army, Navy, and Air Force, Washington, DC, USA, 1991.

[23] W. Wang, Study on Damage Effects and Assessments Method of Reinforced Concrete Structural Members under Blast Loading, National University of Defense Technology, Changsha, China, 2012, in Chinese.

[24] L. Liu, Experimental Study of Differently Protective RC Piers under Blast Loading, Southeast University, Nanjing, China, 2016, in Chinese.

[25] L. Liu, Z. H. Zong, and M. H. Li, "Numerical study of damage modes and assessment of circular RC pier under noncontact explosions," Journal of Bridge Engineering, vol. 23, no. 9, article 04018061, 2018.

[26] B. Tang, Experimental Investigation of Reinforced Concrete Bridge Piers under Blast Loading, Southeast University, Nanjing, China, 2016, in Chinese.

[27] Z. H. Zong, B. Tang, C. Gao, L. Liu, M. H. Li, and S. J. Yuan, "Experiment on blast-resistance performance of reinforced concrete piers," China Journal of Highway Transport, vol. 30, no. 9, pp. 51-60, 2017, in Chinese.

[28] J. Y. Sun, G. Q. Li, and Y. Lu, "Equivalent single degree of freedom model of SRC columns under blast loading," Journal of Vibration and Shock, vol. 26, no. 6, pp. 82-89, 2007, in Chinese.

[29] J. Y. Sun, Research on the Characteristics of SRC Columns Subjected to Blast Loading, Tongji University, Shanghai, China, 2006, in Chinese.

[30] G. D. Williams, Analysis and Response Mechanisms of BlastLoaded Reinforced Concrete Columns, University of Texas, Austin, TX, USA, 2009.

[31] H. M. Elsanadedy, T. H. Almusallam, H. Abbas, Y. A. AlSalloum, and S. H. Alsayed, "Effect of blast loading on CFRPretrofitted RC columns-a numerical study," Latin American Journal of Solids and Structures, vol. 8, no. 1, pp. 55-81, 2011.

[32] L. J. Malvar, J. E. Crawford, J. W. Wesevich, and D. Simons, "A plasticity concrete material model for DYNA3D," International Journal of Impact Engineering, vol. 19, no. 9-10, pp. 847-873, 1997.

[33] Y. F. Hao and H. Hao, "Influence of the concrete DIF model on the numerical predictions of RC wall responses to blast loading," Engineering Structure, vol. 73, pp. 24-38, 2014.

[34] Y. C. Shi, Dynamic Response and Damage Mechanism of Reinforced Concrete Structures under Blast Loading, Tianjin University, Tianjin, China, 2009, in Chinese.

[35] Y. C. Shi, H. Hao, and Z. X. Li, "Numerical simulation of blast wave interaction with structure columns," Shock Wave, vol. 17, no. 1-2, pp. 113-133, 2007.

[36] G. Randers-Pehrson and K. A. Bannister, "Airblast loading model for DYNA2D and DYNA3D," No. ARL-TR-1310, No. ARL-TR-1310, Army Research Lab Aberdeen Proving Ground Md, Harford County, MD, USA, 1997. 


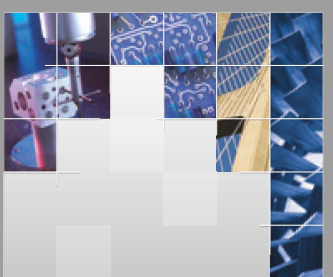

\section{Enfincering}
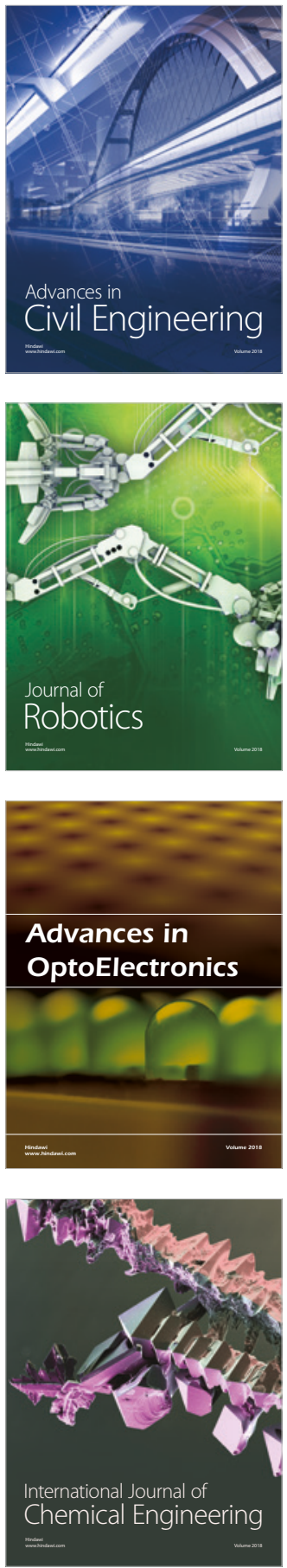

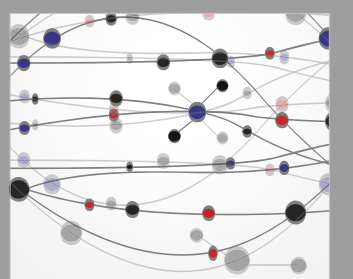

\section{Rotating \\ Machinery}

The Scientific World Journal

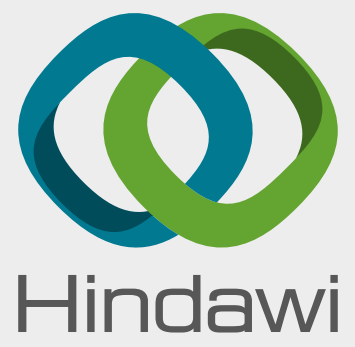

Submit your manuscripts at

www.hindawi.com
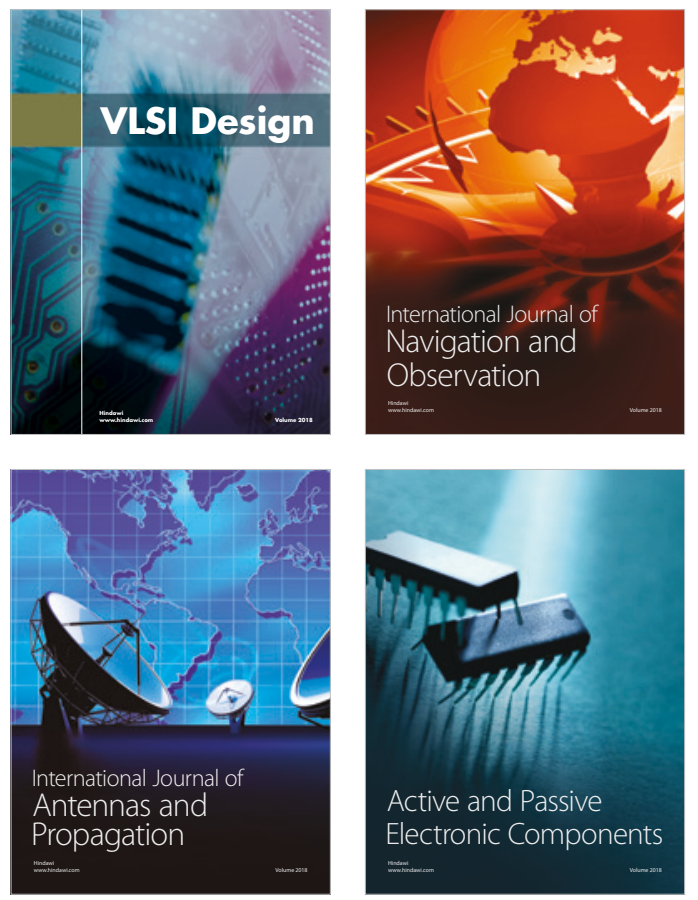
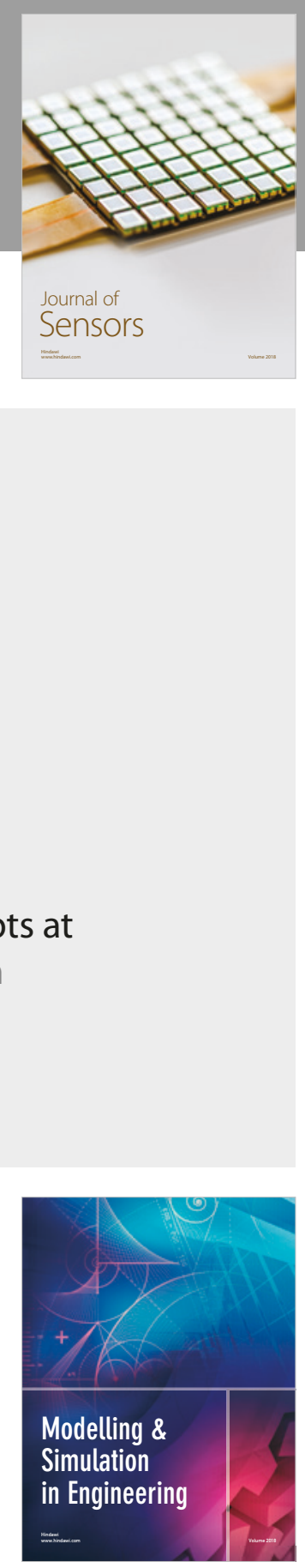

\section{Advances \\ Multimedia}
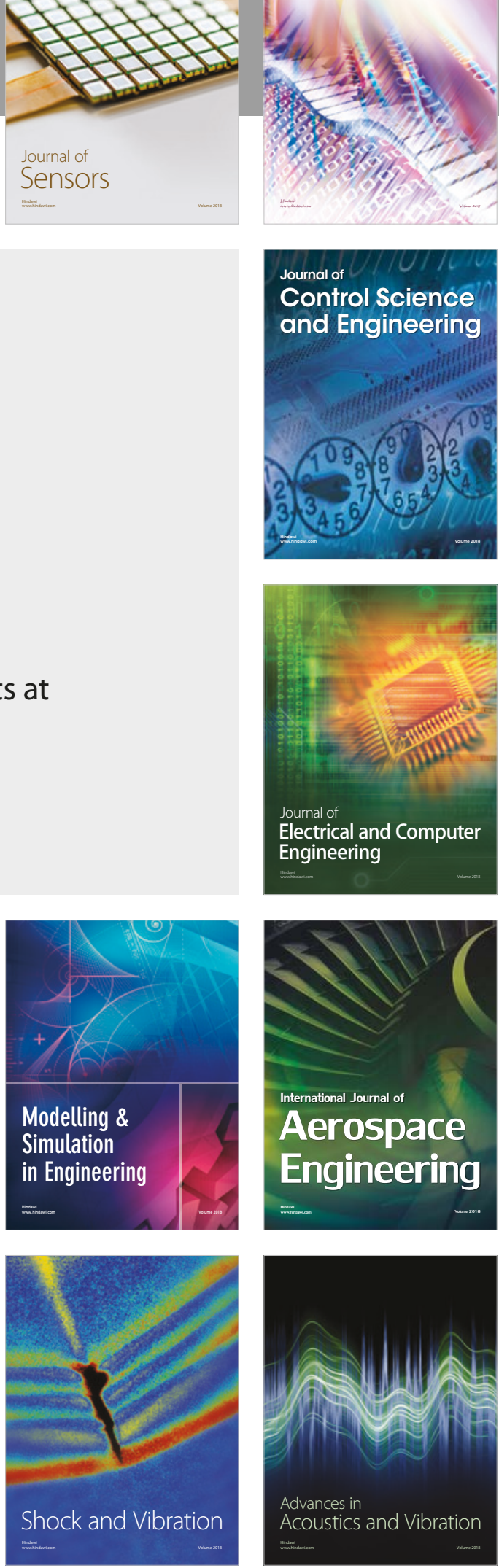